UCID--19934

DEBA 006265

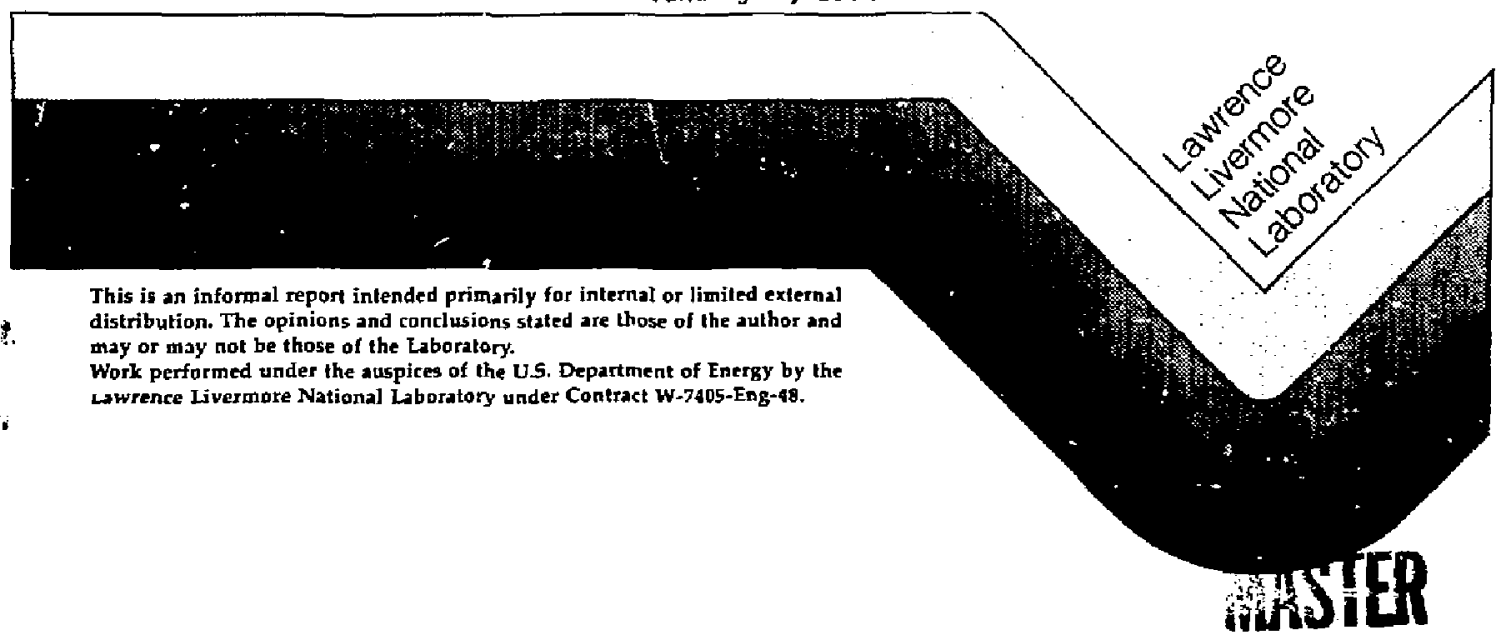

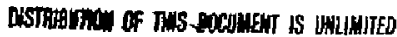




\section{DISCLAMER}

This report was prepared as an account of work spetssored by an agency of the United Stales Governinent. Neither the United Stales Government nof any agency thereof, not any of their employces, makes any wantanty, express of impliad or assumes any legal liability or responsibility for the accuracy, completerness, or uselulness of any information, appatatus, product, or process diselosed, of represents that its use wotid not infinge privately ownert rights. Reference herein to any specific commercial product. process. or service by trade name, trademark. manufacturer, of otherwise does not necessarity constitute or imply its endorsement. recommendation. of favoring by the United Statcs Government of any agency thereof. The views and opirions of authors exgressed herein do not necessarily state or teflecl those of the United Seates Government or any ageacy therear. 


\title{
PRETREATMENT OF KAPTON*-COATED CABLE FOR EPOXY ADHESION
}

\author{
James F. Carley \\ Lawrence Livermore National Laboratory \\ Livermore, California \\ December 15, 1983
}

\begin{abstract}
Preliminary testing of a new system for protecting bonded strain gages that will be attached to the MFTF magnets irdicated falling electrical resistance to ground, attributed to the infiltration of moisture. The most likely infiltration route seemed to be along the Kapton* lead cable, which has an outer surface of FEP fiuorucarbon resin. Samples of the caile were pretreated with a fluorocarbon etchant, Jetra-Etch, for periods of 10, 25, and $40 \mathrm{~s}$ at room temperature, followed by rinsing with demineralized water. The treated ends were embedded in the proposed epoxy sealant, Hysol EA 934, a compound containing $70 \mathrm{wt} \%$ of asbestos. The tensile-shear stresses required to pul] the wires out of these embedments were measured. Results show that the three leveis of treatment are equally effective in raising the bond strength from 377 psi for the untreated cable to about twice that, 763 psi. The 40-s exposure to Tetra-Etch appears to have penetrated the $0.5-m i 1$ fluorocarbon coating and attacked the kapton film and the conductor coatings inside it.
\end{abstract}

\footnotetext{
*Reference to a company or product name does not imply approval or recommendation of the product by the University of California or the U.S. Department of Energy to the exclusion of others that may be suitatle. Kapton is a registered trademark of E. I, duPont de Nemours and Company.
} 


\section{INTRODUCTION}

Seven hundred strain gages are to be atiached to various surfaces of the large magnets of the magnetic fusion apparatus now under construction at LLNL. In the preceding experiment, some of the epoxy-bonded, but uncoated sensars debanded over a year's time during which they were repeatedly taken down to $4 \mathrm{~K}$ and returned to ambient temperatures. It appeared that infiltrating moisture was the cause of the problem. In preparation for the next, larger experiment, improved systems of bonding and protecting strain gages were explored with the aid of an accelerated test in which the test specimens were exposed to $100 \% \mathrm{RH}$ at $120^{\circ} \mathrm{F}$ for varying times. One of the most promising systems, sketched in Figure 1 , is a multilayer construction. It consists of bonding the gage to a stainless-steel substrate (with suitable surface preparation), attaching the 4-wire kapton-coated cable, applying a layer of asbestos-filled epoxy adhesive, covering the assembly with a layer of aluminum foil sealed along its edges with a nitrile-rubber sealant, then overlaying this with a second layer of the epoxy adhesive, Hysol EA 934. The Kapton wire was chosen over other candidates because of its high resistance to damage from neutron radiation. EA 934 was chosen for its excellent bonding properties, resistance to moisture and low thermal expansion (due to its high asbestos content).

When test gages prepared according to this recipe, but lacking the second EA 934 overcoat, were exposed to $100 \% \mathrm{RH}$ at $120^{\circ} \mathrm{F}$ for some days, some showed a reduced eiectrical resistance to ground. We noticed, too, that the bond of the EA 934 along the surface of the leadwire cable seemed to pull apart easily, making that interface a prime suspect as a penetration route for moisture. I was asked to investigate this possibility and to suggest ways of improving the bond. In the short time available before the work of attaching gages to the MFTF magnets had to begin, it was felt that wholly new systems of gage bonding and sealing could not be initiated. 
APPKOACH TAKEN AND EXPERIMENTS MADE

In conversation with BarCal Wire and Cable, suppliers of the leadwire, I learned that the Kapton film used in the final wrap of the cable was coated with FEP fluorocarbon resin on both sides. This coating is heat-fusible, which the Kapton polyimide material itself is not; by passing it though an oven after wrapping, a continuous, moisture-resistant overcoat is generated. However, fluorocarbon resins ("Tefion") are noted for their very poor adhesion properties, and for the strenuous pretreatments that must be applied to them in order to make them adherable with common adhesives. It seemed likely that by removing the FEP film on the outside of the cable, or by pretreating it, we might achieve better bonds to the EA 934 .

I first tried soaking the ends of some cable samples in boiling hexefluorobenzene (HFB), a chemical listed in the Polymer Handbook as a solvent for poly(hexafluoropropylene), a polymer closely related to FEP copolymer. Boiling times of 2,4 , and $24 \mathrm{~h}$ were used. There was no change in the appearance or texture of these cable ends, but the samples were given to James $W$. Fischer, who examined their surfaces by $x$-ray photoelectron spectroscopy, a technique of surface analysis which was capable of finding any fluorine present. Dr. Fischer reported strong $F$ and $C-F$ signals from the untreated and treated samples, indicating tc me that the boiling treatments had not remoled the $F[P$ half-mil coating.

A commercialiy available etchant for fluorocarbons is Tetra-Etch, made by W. L. Gore and Associates. Bill Barnes of BarCal said they routinely treat cable with Tetra-Etch and recommended 20 to $30 \mathrm{~s}$ immersion at room temperature, follawed by rinsing in dejonized water. To test this reagent's effectiveness in our system, I planned the following experiment. Fifteen wire samples were cut and straightened as well as I could manage with my fingers. Six were left untreated; the ends of the others were etched. Three each were imersed in Tetra-etch for $10 \mathrm{~s}, 25 \mathrm{~s}$ and $40 \mathrm{~s}$, and imediately rinsed thoroughly with deionized water* and dried with a clean wipe. The wires were arranged vertically in a rack with the treated ends down. A small amount of EA 934, thoroughly mixed, was placed in each of 15 -cc polyethylene cups with

*one should not confuse this with unionized water, in which all the molecules are members of the Amalgamated Brotherhood of HOH Workers. 
an inside bottom circumference of $3 / 4$ inch. The cups were centered beneath the wire ends which were then pressed down inta the soft (but stiff) epoxy mix and allowed co stand overnight. The cure was completed by placing the embedded wires in an air oven at $200^{\circ} \mathrm{F}$ for an hour. The finished embedment looked as sketched in Figure $2 A$.

A tensile-adhesion-test set up was devised for an Instron Model TTOM testing machine located in 231 Building. As Figure $2 A$ shows, the upper surfaces of the epoxy plugs were uneven, since this material is too stiff to flatten out by gravity and is difficult to flatten with a spatula. To accomodate this unevenness, I made a laminated washer consisting of ordinary ilat steel washers cemented together, one $7 / 8-i n$ OD, 3/8-in ID, the other $3 / 4-$ in $0 D, 5 / 16$-in 10 , to which was cemented a felt washer of the same 10 , 0.7 -in 00 , and 0.2 -in thickness (Figure $2 B$ ). When the specimen was pulled, the felt surface was pressing against the upper surface of the epoxy plug and tl.: steel surface was retained by the grip of the testing machine. A plotter recorded the force-cell signal and the crosshead displacement. From those plots were obtained the breaking loads; these were uses to calculate the shear stresses at failure.

Each of the epoxy plugs pulled away in one piece. Because of the unevenness of the upper surface, the depth of the shear surface in each plug varied considerably around the circumference. To obtain a representative mean depth, each plug was cut along a diameter by a sharp biow with a surgical scalpel, and the depth was measured along four elements around the circumference and the four values averaged. In six of the plugs there were bubbles impinging the shear surface; the unfilled part of the hole height was deducted prior to averaging. The wide variation in these depths was the largest source of variation in the breaking strengths.

Specinens 13, 14 and 15 , exposed for $40 \mathrm{~s}$ in Tetra-Etch, showed fragments of the cable covering adhering to the epoxy plug with corresponding tears and gaps in the cable ends. This seemed to indicate that the etchant had entirely removed the FEP coating and, perilaps, had weakened the underlying polyimide. Cable specimen No. 14 was taken to $\mathrm{JIm}$ Fisher for surface analysis. iim found that there was still detectable $F$ present, but that the wrap was flimsy and the etchant seemed to have penetrated the wrap and dullec the insulation on the wires inside. 
RESULTS AND RECOMMENDATIONS

The data and calculated shear stresses at failure are listed in Table 1.

For the 6 specimens that were cleaned but untreated, the mean stress at failure was $377 \mathrm{psi}(2.60 \mathrm{MPa})$, the standard deviation was $98 \mathrm{psi}(0.68 \mathrm{MPa})$, and the standard error of the mean was $40 \mathrm{psi}(0.28 \mathrm{MPa})$.

For specimens $7-9$, etched for $10 \mathrm{~s}$, the corresponding figures are 773,25 and $14.5 \mathrm{psi}(5.33,0.17,0.100 \mathrm{MPa})$.

For specimens 10-12, etched $25 \mathrm{~s}$, the corresponding figures are 762,154 , and 89 psi $(5.25,1.06,0.61 \mathrm{MPa})$. The much larger standard deviation here is due to the very low failure stress of No. 11.

For specimens 13-15, etched $40 \mathrm{~s}, \mathrm{ti}$ : figures are 757,54 and 31 ps $j$ $(5.22,0.38,0.22 \mathrm{MPa})$.

Clearly, the three levels of treatment provided nearly equal mean shear strengths. The strength was more consistent at $10 \mathrm{~s}$ than at 0,25 or $40 \mathrm{~s}$, however, this difference in variance is not statistically significant at the 95\% level (risk of Type I error $=0.05$ ). Pooling the sums of squares and degrees of freedom (11) for 21115 specimens provides a pooled standard deviation of $96.8 \mathrm{ps}$. When this value is used to test the significance of the difference between the treated and untreates means, 387 psi, the $t$-value is +7.59 , far beyond any reasonable critical value. Etching makes a big, real difference:

Considering the apparently severe attack of the kapton overwrap at $40 \mathrm{~s}$, and the evidence of etchant penetration into the cable end, 1 recorinend that the cable be treated for $10 \mathrm{~s}$ in Tetra-Etch at room temperature, as shown in Figure 3, and immediately be thoroughly rinsed with demineralized water, dried, and cut off. After the electrical connections have been made, the length of cable that will be embedied in EA 934 should be wiped with alcohol and allowed to dry prior to applying the adhesive. Care should be taken in applying the final overcoat to make sure that plenty of EA 934 gets beneath the cable and completely wets and surrounds the entire circumference. 
Table 1. Bond Strength Measurentents

\begin{tabular}{|c|c|c|c|c|c|}
\hline Number & $\begin{array}{l}\text { Time of Exposure } \\
\text { to Tetra-Etch } 5\end{array}$ & $\begin{array}{l}\text { Bond Area, } \\
30^{-3} \text { in }^{2}\end{array}$ & $\begin{array}{l}\text { Load at } \\
\text { Failure } 1 b_{f}\end{array}$ & \multicolumn{2}{|c|}{$\begin{array}{l}\text { Shear Stress at } \\
\text { Fai lure, } \\
\text { psi }\end{array}$} \\
\hline 1 & 0 & 70.5 & 24.4 & 346 & 2.39 \\
\hline 2 & 0 & 56.9 & 23.8 & 418 & 2.88 \\
\hline 3 & 0 & 49.5 & 26.4 & 533 & 3.68 \\
\hline 4 & 0 & 72.1 & 18.0 & 250 & 1.72 \\
\hline 5 & 0 & 61.4 & 19.0 & 309 & 2.13 \\
\hline 6 & 0 & 50.3 & 20.3 & 404 & 2.78 \\
\hline 7 & 10 & 25.4 & 19.7 & 776 & 5.35 \\
\hline 8 & 10 & 34.3 & 27.3 & 796 & 5.49 \\
\hline 9 & 10 & 27.6 & 20.6 & 746 & $5 . i 5$ \\
\hline 10 & 25 & 24.0 & 21.0 & 875 & 6.03 \\
\hline 11 & 25 & 45.9 & 26.9 & 586 & 4.04 \\
\hline 12 & 25 & 37.6 & 31.0 & 824 & 5.68 \\
\hline 13 & 40 & 29.9 & 24.0 & 803 & 5.53 \\
\hline 14 & 40 & 37.6 & 29.0 & 771 & 5.32 \\
\hline 15 & 40 & 42.6 & 29.7 & 697 & 4.81 \\
\hline
\end{tabular}




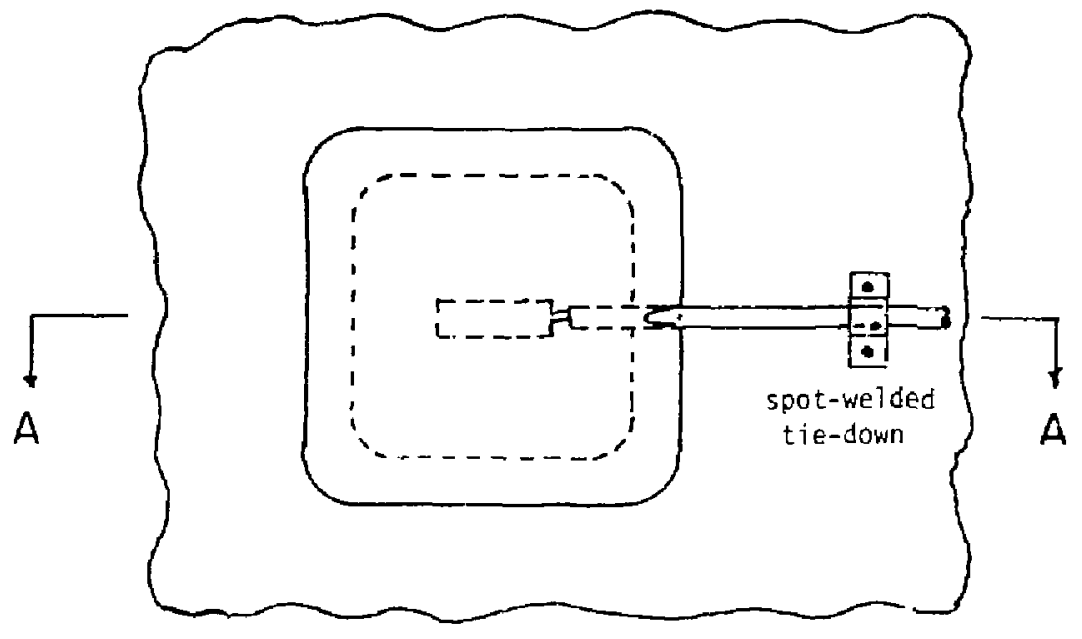

Section A-A

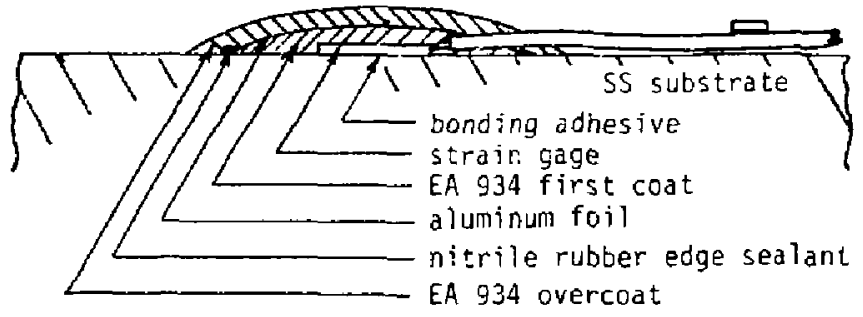

Fig. 1: Proposed multilayer system for bonding and prctecting MFTF strain gages. 

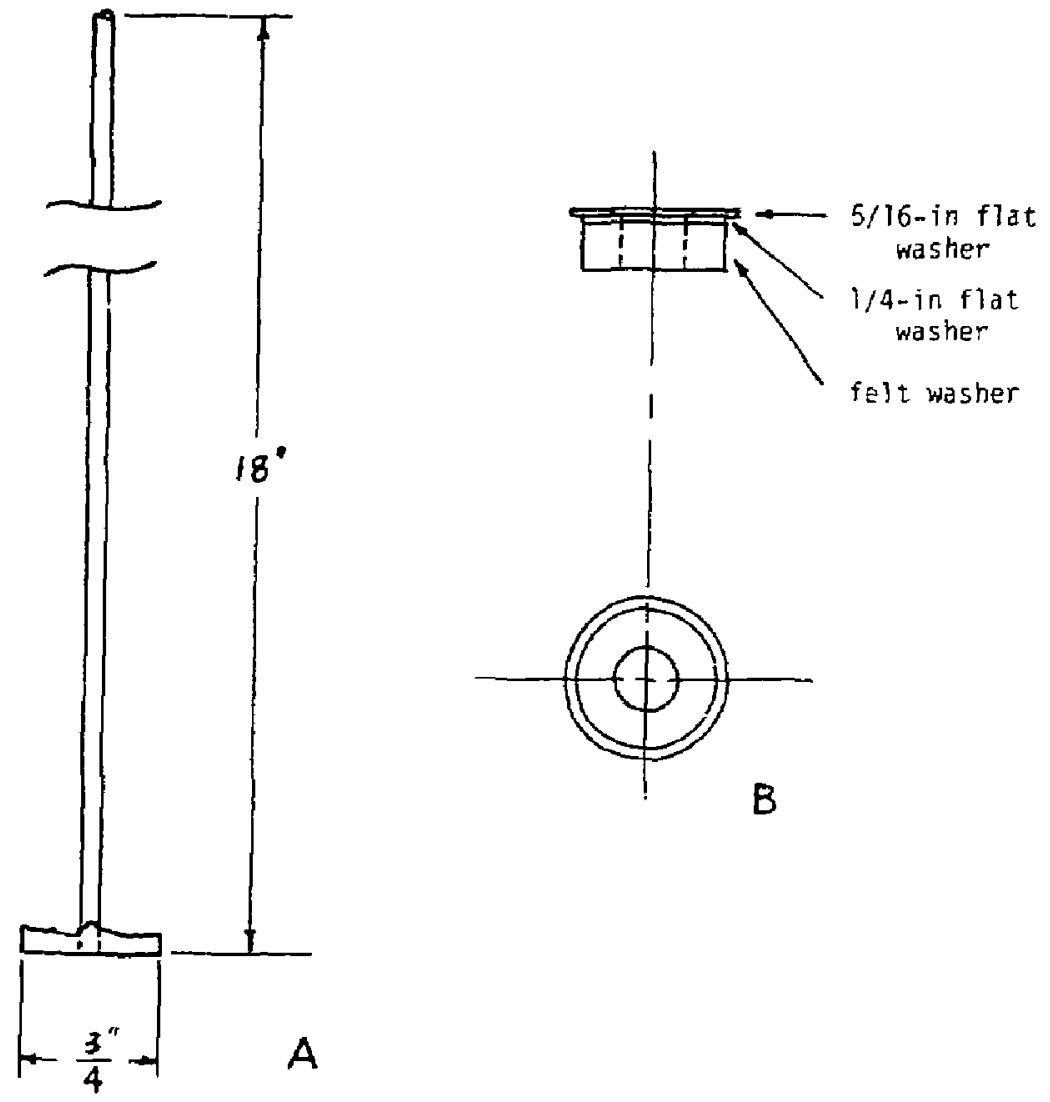

Fig. 2: A is a profjle view of test specimen of kapton cable embedded in EA 934 epoxy plug. B shows cushioned wastier whose face was set against upper face of plug during tensile-shear test. 


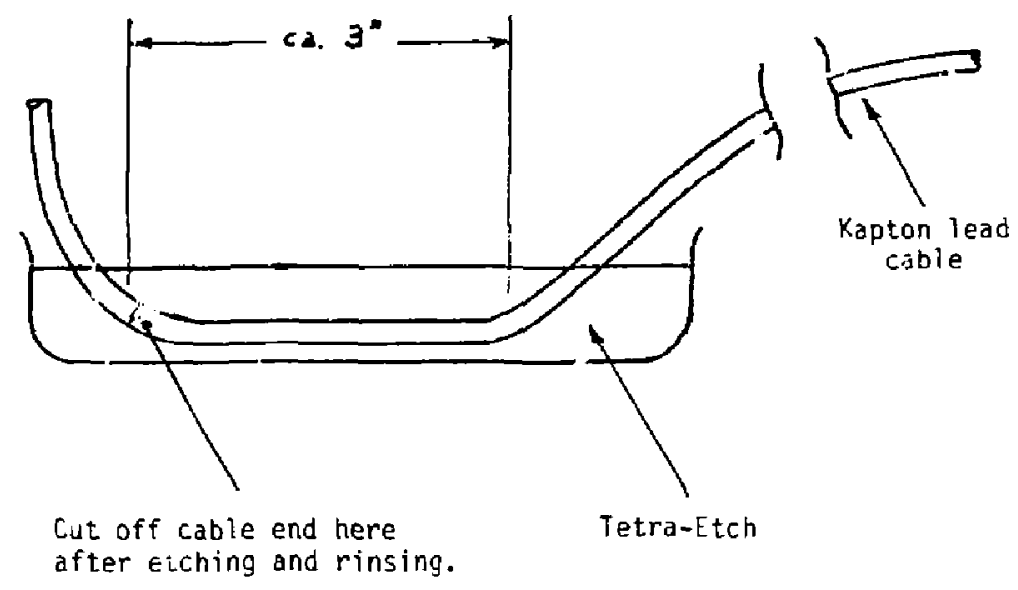

Fig. 3: This shows suggested way to etch end of Kapton lead cable hat will be embedded in EA 934 adhesive overcoat, without ailowing Tetra-Etrih to infilirate cable end. 